\title{
Development and exploitation features of methane-coal wells using downhole pumping equipment
}

\author{
Elena Kurganova ${ }^{1}$, Alexandra Makarovskikh $^{1 *}$, Tatyana Chernykh $^{1}$ \\ ${ }^{1}$ Tomsk Polytechnic University, 30 Lenin Ave., Tomsk, 634050, Russia
}

\begin{abstract}
In this article extraction of methane from coal beds is presented. The article presents results of the study of downhole pumping equipment used in the exploitation of coal bed methane wells. The features of various types of equipment such as piston sucker-rod pumping units, electrical centrifugal pumping units and sucker-rod screw pumping units have been considered. The results show benefits of sucker-rod screw pumping units because of their versatility and resistance to higher content of mechanical impurities.
\end{abstract}

\section{Introduction}

Nowadays natural resources use tends to be effective. As a result there is a necessity of natural methane gas use for industrial and domestic needs (fuelling, lighting, etc).

A coalfield in Kuznetsk (Kuzbass) is one of the most perspective and prepared regions for methane extraction from gasbearing coal beds in Russia.

Actually Kuzbass has no equals among the famous coal basins of the world. It has unique coal-gas-related characteristics:

- coal-bearing formation presented by the most preferable coal rank in terms of methane-bearing capacity with a stack height up to $90-120$ meters with a methane content of $25-30 \mathrm{~m}^{3} / \mathrm{t}$;

- $\quad$ high concentration of methane resources in coal beds - up to $3 \mathrm{bcm} / \mathrm{km}^{2}$;

- cumulative methane influx in coal beds of the basin (up to the depth of $1800 \mathrm{~m}$ ) is about 13 tcm over the area of 21 thousand square kilometers. Moreover, in the most promising regions of the south (Erunakovskij, Tersinskij, Tom-Usinskij, Mrasskij) estimated resources are ranged from 0.9 to $3.2 \mathrm{tcm}$, and in some promising areas $-100-480 \mathrm{bcm}$. Gas is substantially pure and does not require additional purification [3].

Industrial infrastructure which is established in Kuzbass creates exceptionally favorable conditions for the organization of methane production from coal deposits. Methane which is extracted from coal beds via drilled wells is environmentally friendly hydrocarbon feedstock used for the region gasification as well as in industry, gas chemistry as a motor fuel, etc.

The optimization of gas-related equipment at all stages of production and preparation of gas for transportation plays an important part in solving the above-listed problems. Moreover, the stage of gas production largely determines the efficiency of the methane-coal complex operation as a whole. Therefore, in this situation, the optimal use of downhole equipment and the extension of service life get their applicability [4].

\section{Materials and Methods}

The aim of this work is to analyze the efficiency of wells mechanized with gas-oil equipment on NarykskoOstashkinskaya field, as well as a competent evaluation and selection of advanced technologies for removing operational defects that lead to equipment failure in definite wells to ensure their safe performance and reduce the extraction cost of formation fluid.

The development of methane-coal wells is fulfilled in two stages. The first stage is characterized by intense carrying out of fluid after fracturing with a high content of mechanical impurities: proppant, clay mud, coal slime. When the formation water is pumped out, a dynamic fluid level of the well decreases and it is necessary to control a start of the gas desorption, which is accompanied by changing of gas pressure in the annular space. It is particularly important to monitor condition and properties of the pumped liquid (color, contamination, etc). For example, dark water with coal dust indicates a start of the coal bed destruction, which leads to the mudding of the formation zone bottomhole. The

\footnotetext{
* Corresponding author: alexandravm1@rambler.ru
} 
results obtained in a specialized laboratory have shown that the average content of solids in pumping fluid at the wells of Taldinskaya area is $12 \mathrm{mg} / \mathrm{l}$. At the wells of Naryksko-Ostashkinskaya area the same value is $406 \mathrm{mg} / \mathrm{l}$. Consequently, at the initial stage of the well development there is a considerable cuttings lifting and while an operating process the content of suspended matters is multiply reducing. Therefore, the objectives of the first stage of the development are:

- mechanical impurities removal;

- minimization of the failures of downhole equipment which will be used during the trial operation;

- indirect identification of potential flowrates of water and gas.

At the initial stage of the development pumping equipment arrangement for pumping formation fluid was lowered into the well to a depth of $300-450 \mathrm{~m}$. $50 \mathrm{~m}$ above the upper bed depth is the best depth for downhole pumping equipment arrangement at the first stage of the development [4]. If a well is not subjected to hydraulic fracturing, the first stage of the development is excluded. The stage makes it more accurately determine the potential of the well flowrate of gas and water, as well as choose the most appropriate type and size of pumping equipment for the second stage which consists of the output to the steady-state exploitation and maximum elimination of the risk of clogging up of gas-oil equipment.

At the second stage of the development different types of downhole equipment units are used: piston sucker-rod pumping units, sucker-rod screw pumping units and electrical centrifugal pumping units (figure 1).
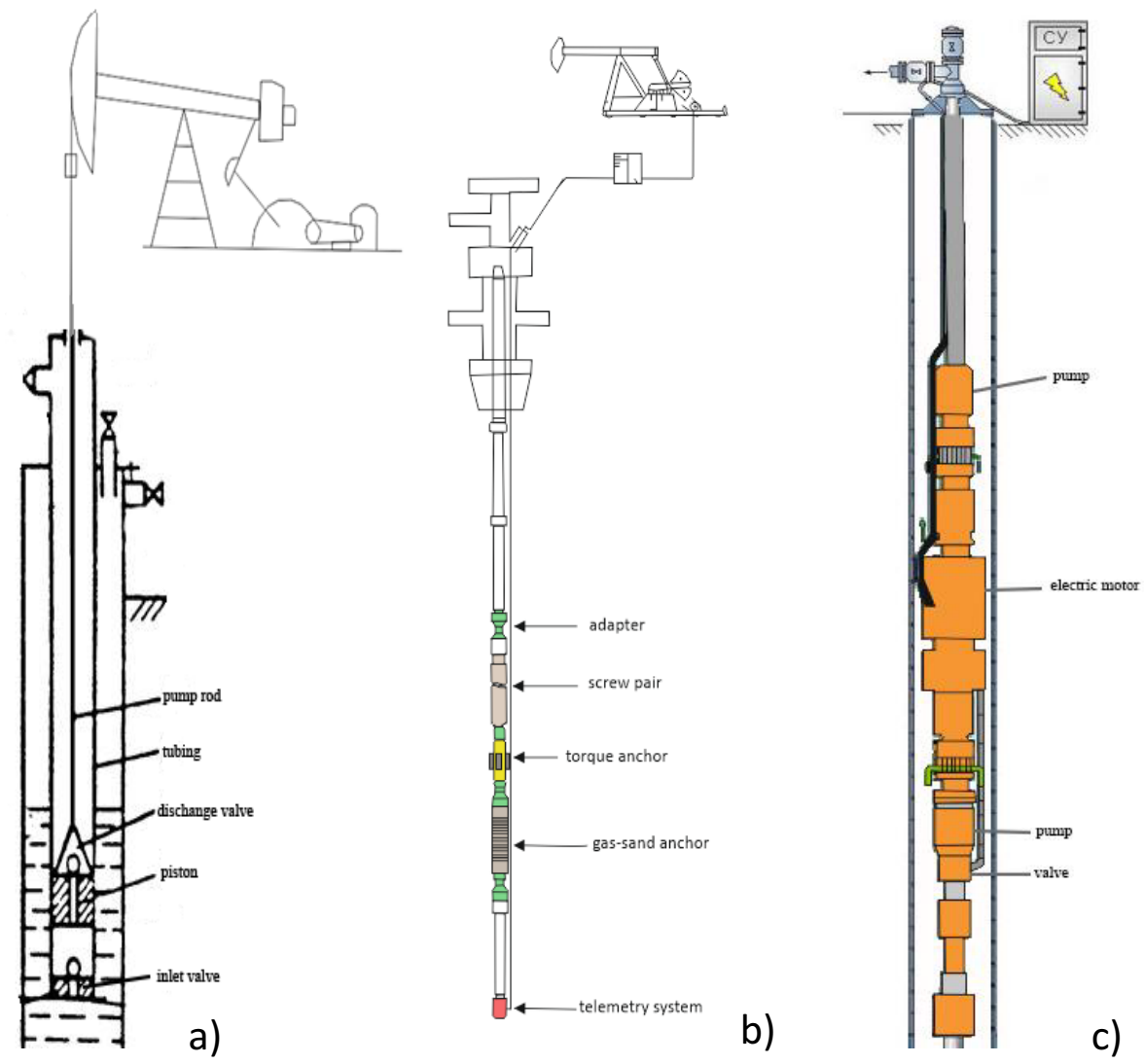

Fig. 1. Pumping units: a) piston sucker-rod pumping units (PSRPU); b) sucker-rod screw pumping units (SRSPU); c) electrical centrifugal pumping units (ECPU).

In 2002-2003 in Kuzbass during the gas-dynamic research at the exploration well the use of piston sucker-rod pumping units to pump formation fluid was first experienced [5].

The application of piston sucker-rod pumping units has not received extensive use due to some reasons: clogging of valves with mechanical impurities, inability to backwash and absorption of flush fluid by productive formations. Besides, at the second stage of the development there are electrical centrifugal pump units, which are used, if water influx permits and it is a steady-state exploitation. This type of pumping equipment has a high overhaul period at methane-coal wells. The main reasons of failure of this type of equipment: 
- isolation reduction in cable link;

- work tool wear;

- pump jamming.

About $84 \%$ of the reasons for failure are connected with clogging with mechanical impurities. The mean time between failures of electrical centrifugal pumps is 162 days in the fund (for the period from 2009 to 2012) [1]._Sucker-rod screw pumping units receive widespread application because they are the most versatile for methane-coal field conditions [3]. The main reasons of failure of this type of equipment:

- leakage and drop of tubing;

- drop and breakage of rods;

- pump jamming.

The mean time between failures of sucker-rod screw pumps is 99 days in the fund (for the period from 2009 to 2012) $[1]$.

\section{Results and Discussion}

Thus, for the exploitation of methane-coal wells the most optimal types of downhole equipment are sucker-rod screw pumping units. Therefore, it is reasonable to use sucker-rod screw pumping units because of their resistance to higher content of mechanical impurities in the pumped formation fluid and versatility (at all stages of the development). It is recommended to meet the following conditions:

1. Exclusion of a gas-sand anchor from the packaging arrangement to minimize the risk of further failure of sucker-rod screw pumping units at the initial stage of wells development;

2. Optimal centralizers application and allocation to reduce mechanical wear upon contact with the sucker rod of tubing and extend its service life;

3. Application of the dynamic torque anchor A-168 as part of the sucker-rod screw pumping units to avoid threaded connections drops when screw pair jamming;

4. Use of a downhole telemetry system with a minimum grade value of 0.01 Bar.

5. If possible, elimination of gas-oil equipment operation in periodic mode [2].

Currently, 17 downhole pumping units are exploitated at the LLC "Gazprom dobycha Kuznetsk" at the wells of Taldinskaya and Naryksko-Ostashkinskaya areas. There are sucker-rod screw pumping units (SRSPU) and electrical centrifugal pumping units (ECPU) of various types and sizes. Figure 2 shows distribution of the current fund by the number of pumping units at the wells of Taldinskaya and Naryksko-Ostashkinskaya areas. Preference is given to using sucker-rod screw pumping units $(71 \%)$.

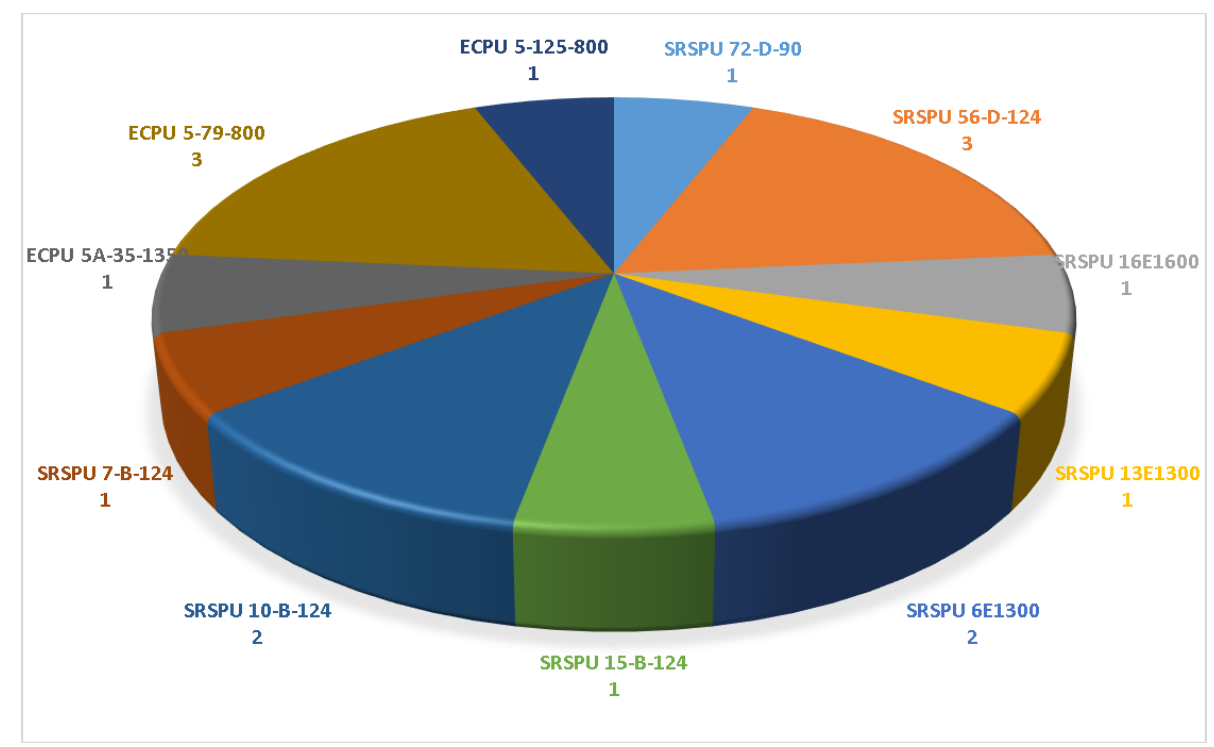

Fig. 2. Current fund of pumping units used for pumping formation fluid at the wells of Taldinskaya and Naryksko-Ostashkinskaya areas.

\section{Conclusion}


As a result a sucker-rod screw pumping unit has been offered due to the duration of the equipment, revenue position and operating efficiency. This type of setting is primarily used for pumping out formation water. The use of methane-coal beds is economically advantageous [5], first of all due to the comparatively inconsiderable transportation leg from the field to the consumer. In addition, the methane content in the coal gas reaches $98-99 \%$, which means no additional costs for purifying and processing gas before shipment [6].

\section{References}

1. Gas-dynamic research at the well № 16320 at the Taldinskaya area in Ermakovskij region of Kuzbass (by contract report №4 dated 02.10.2002)

2. A.N. Drozdov, The use of downhole fluid-jet pumping units for operation in abnormal wells Oil and gas vertical 12, 70-73 (2009)

3. A.M. Karasevich, Methodology and management of the regional gas-supply systems development The Abstract of doctoral thesis in Engineering Science (Irkutsk, 2003)

4. R.R. Lopatin, Models and algorithms of the frequency-regulated process of jamming the electrical centrifugal pump in oil production in abnormal operating conditions The Abstract of PhD thesis in Engineering Science (Tomsk, 2011)

5. P.N. Parmuzin, Estimate the economic effect in the project for methane recovery from coal seams Problems of economy and management of oil and gas complex 3, 15-17 (2013)

6. G.S. Spitsin Gas from coal beds Electronic resource, URL: http://twidler.ru/referat/geografiya/gaz-iz-ugolnyhplastov-39611 (Access date 02.07.2016) 